\title{
Comment on: "The effect of corticosteroid on postoperative early pain, renal colic and total analgesic consumption after uncomplicated and unstented ureteroscopy: a matched-pair analysis"
}

\author{
Mark C. Kendall ${ }^{1}$
}

Received: 1 May 2018 / Accepted: 3 May 2018 / Published online: 15 May 2018

(c) Springer-Verlag GmbH Germany, part of Springer Nature 2018

\section{Dear Editor,}

I read with great interest the article by Hamidi et al. [1] in a recent issue of the journal. The authors performed a retrospective study on 397 patients who underwent unstented ureteroscopy and concluded that corticosteroid after uncomplicated unstented ureteroscopy can be offered to reduce early postoperative pain, renal colic episodes and total analgesic consumption. The authors should be congratulated for performing a well-designed study on an important topic (e.g., acute pain) in patients undergoing urologic procedures $[2$, $3]$. The current emphasis on the need to reduce the use of opioids by using multimodal analgesic strategies makes the topic very relevant in perioperative medicine $[4,5]$.

The study of Hamidi et al. was well conducted; however, there are several questions regarding the study that need to be clarified by the authors. First, it is unclear if the patients received standardized intraoperative analgesics as this can significantly affect the postoperative outcome of the study. Second, dexamethasone (another corticosteroid) is commonly given intraoperatively to prevent postoperative nausea and vomiting. It is unknown if the patients in this study received intraoperative dexamethasone confounding the author's findings. Last, the authors evaluated multiple outcomes, but did not account for type I errors which may change the author's conclusions.

This comment refers to the article available at https://doi. org/10.1007/s00345-018-2210-1.

Mark C. Kendall

mark.kendall@lifespan.org

1 Department of Anesthesiology, Rhode Island Hospital,

Warren Alpert Medical School of Brown University, 593

Eddy Street, Providence, RI, 02903, USA
I would welcome comments to address the aforementioned issues, as this would help to further support the findings of this important retrospective study.

\section{Compliance with ethical standards}

Conflict of interest The author declares no conflicts of interest and has nothing to disclose.

\section{References}

1. Hamidi N, Ozturk E, Yikilmaz TN, Atmaca AF, Basar H (2018) The effect of corticosteroid on postoperative early pain, renal colic and total analgesic consumption after uncomplicated and unstented ureteroscopy: a matched-pair analysis. World J Urol 2:1-6. https://doi.org/10.1007/s00345-018-2210-1 (Epub ahead of print)

2. Hou YY, Li Y, He SF, Song J, Yu DX, Wong GTC, Zhang Y (2017) Effects of differential-phase remote ischemic preconditioning intervention in laparoscopic partial nephrectomy: a single blinded, randomized controlled trial in a parallel group design. $\mathrm{J}$ Clin Anesth 41:21-28

3. Jairath A, Ganpule A, Gupta S, Mishra S, Sabnis R, Desai M (2017) Can intraperitoneal bupivacaine decreases pain in patients undergoing laparoscopic live donor nephrectomy? A randomized control trial. World J Urol 35:985-989

4. Zhang Z, Xu H, Zhang Y, Li W, Yang Y, Han T, Wei Z, Xu X, Gao J (2017) Nonsteroidal anti-inflammatory drugs for postoperative pain control after lumbar spine surgery: a meta-analysis of randomized controlled trials. J Clin Anesth 43:84-89

5. De Oliveira GS, Bialek J, Rodes ME, Kendall MC, McCarthy RJ (2017) The effect of sevoflurane compared to propofol maintenance on post-surgical quality of recovery in patients undergoing an ambulatory gynecological surgery: a prospective, randomized, double-blinded, controlled, clinical trial. J Clin Anesth 43:70-74 